\title{
Local authority instrumental music tuition as a form of neo-liberal parental investment: findings from a deviant, idiographic case study
}

\author{
Ross Purves \\ Associate Professor of Music Education \\ Department of Culture, Communication and Media \\ University College London Institute of Education
}

\begin{abstract}
Local authority music services have held a central place in the UK's music education landscape since the end of the second world war. Nonetheless, the provision of these services has always been a non-statutory responsibility and local levels of opportunity have varied in response to prevailing economic and political climates, along with broader developments in educational policy. The first half of this paper focuses on the implications of two key policies enacted during the 1990s. Both were linked to perceived changes in the profiles of young people who engaged with music service tuition. The latter half presents an ecological study of practical implications of the second policy - the 'Music Standards Fund' - on primary-aged children's take up of, and persistence with, the tuition in one English local authority. At both area and school levels, the children's engagement cohered with various socio-economic and contextual factors. This coherence is considered from the perspectives of Connell's 'neo-liberal parent' and related, Bourdieusian-influenced theories. The conclusion offers implications from the implementation of the policy in the contemporary era of 'Music Education Hubs', the successor organisations to local authority music services, and the schools these hubs serve.
\end{abstract}

\section{Key words}

music education; instrumental tuition; local authority music services; education policy; ecological study; neoliberal parenting; resource boosters; concerted cultivation

\section{Introduction}

Local authority music services have held a central place in the UK's music education landscape since the end of the Second World War (Rainbow and Cox, 2006). They have been important providers of instrumental tuition, local youth ensembles, extracurricular 'music schools', instrumental loans and many other kinds of support (Ofsted, 2004). Nonetheless, the provision of these services has always been a nonstatutory responsibility and local levels of opportunity have varied in response to prevailing economic and political climates, along with broader developments in educational policy (Rogers and Hallam, 2010). Consequently, throughout music services' existence particular concerns have been raised that some groups of pupils have been less able to access and sustain engagement with the instrumental tuition on offer (Hallam, 1998). In particular, primary learners were less able to participate 
due to a focus on the musical development of older pupils (Cleave and Dust, 1989; Rogers and Hallam, 2010).

The first section of this paper focuses on the implications of two key policies implemented during the 1990s: the 1988 Education Reform Act (ERA) and the 1999 Music Standards Fund (MSF). Both were linked to perceived changes in the profiles of young people who took up and persisted with local authority music service instrumental tuition. The second section presents an ecological study of the practical impacts of the MSF on primary-aged children's engagement with music service tuition in one English local authority. An ecology of factors associated with this engagement is considered through Connell's (2008; 2011) neo-liberal parent concept. Such parents are characterised as particularly adept at 'scanning the market' (Connell, 2008: 188) to identify advantageous educational opportunities for their children. Analysis also draws on further, Bourdieusian-influenced theories including Lareau's (2002) idea of concerted cultivation and Coleman's (1990) resource boosters concept. Long-standing concerns regarding a range of 'hidden' barriers to music service tuition such as vehicle ownership and local environment factors are also considered.

Since the enactment of the National Plan for Music Education in 2012 (DfE/DCMS, 2011) most English music services have been repositioned as the 'lead organisations' for their local 'music education hubs', with a remit to work in close partnership with the schools they serve (Widdison et al, 2017). Therefore, the paper concludes with recommendations as to how findings might inform the operating practices of both hubs and schools.

\section{Policy Context}

\section{The Education Reform Act}

The ERA led to extensive rationalisation and reorganisation amongst local authority music services. Local Management for Schools (LMS) and the granting of permission to charge for non-statutory activities meant adapting to an unfamiliar climate characterised by the 'new era values' (Bonnett, 1996: 27) of consumer choice and full economy costing (Finney 2011). In Bourdieu's terms, what might once 
have been well characterised as a 'field of restricted production' (1984: p4) in which the cultural goods being produced (i.e. young people's acquisition of instrumental skill and musicianship) were primarily intended for consumption by other, similarlypositioned producers, was now subject to significant colonisation by the generalised economic field of which it was part. Assessments of ERA's impact on music services were mixed. On one hand, some services were able to extend their reach to greater numbers of schools and more diverse groups of pupils by taking advantage of entrepreneurial opportunities afforded by LMS (Coopers and Lybrand/MORI, 1994; PRS, 1999). Primary pupils in particular stood to benefit. With their new status as customers, some primary headteachers used devolved funds to buy back increased music service tuition, reducing longstanding inequalities with their secondary colleagues in the process (Sharp, 1991). Consequently, the proportion of primary schools served by their local music service rose from 64\% in 1991 to approximately $75 \%$ two years later (Coopers and Lybrand/MORI, 1994).

On the other hand, the associated financial disruption ultimately led to between an estimated 30 to 50 music services being deemed economically unviable and closing altogether (Ridgeway, 2002; Annetts, 2010). There are suggestions that closures were more frequent in poorer areas (Rainbow and Cox, 2006). Many other services introduced higher charges to parents (Sharp, 1995). By 1998, 79\% of parents of primary-aged music service pupils were paying for lessons, a figure which had tripled since 1993 (PRS, 1999). Yet only $28 \%$ of primary schools had parental fee remission policies to cover the cost of tuition bought back from their local music service.

Such a mixed picture contrasted with contemporary official views that marketisation had potential to reduce inequity in the education system as a whole (Hill and Kumar, 2012). Horsley's (2014) extensive research into English music education policy of this period highlights many inherent contradictions between ministerial desires to reduce the role of the state on the one hand, but retain musical opportunities for the many on the other. As Horsley (2015: 73) observes, the goal of 'equal access for all' in music education is superficially consistent with neo-liberal educational discourse. Yet this is largely because the latter often downplays the influence of socio-economic and other demographic and contextual factors in its concern to promote notions of 
choice, personal responsibility and economic self-interest. Thus, argues Horsley, this equality of access is not typically achieved in practice.

\section{The Music Standards Fund}

Three large-scale surveys into young people's instrumental learning were undertaken by the Associated Board of the Royal Schools of Music (ABRSM, 1994; $1997 ; 2000)$. These illuminated the apparently unequal participation of children from different socio-economic backgrounds in the period following the introduction of LMS. They offered ammunition to those lobbying the incoming Labour government for greater financial support for local authority instrumental tuition (Morris, 2000; Wright, 2013). Ministers subsequently introduced the MSF from January 1999, intended to 'protect and expand' (Ofsted, 2004: 2) remaining music service provision through the provision of central government funding direct to local authorities.

Over time, the MSF became a key driving force behind the Government's pledge that 'every child should get the opportunity to learn an instrument' (Blunkett, 1998: 13). This was the first occasion central government had ever contributed financial support to local authority music services, and the sums of money involved were large. Between 1999 and the end of the MSF in 2011, over three-quarters of a billion pounds was distributed directly to music services in England (HC Hansard, 2008; DCSF, 2009). Ministers were clear that this money was to be used to develop highquality provision which was accessible to as many young people as possible, irrespective of socio-economic background (M2 Communications, 2000). To this end, local authority bids for MSF allocations were partially assessed on 'the number of young people benefitting from funded provision' and 'the extent to which the bid improved equality of access to music services' (DfEE, 1998b: Section 27a).

The direction of travel, established in the 1990s, towards schools, parents and thirdparty sources meeting more of the costs continued into the next decade (Annetts, 2010). However, evidence began to indicate that government intentions to widen participation through the MSF were beginning to bear fruit. Hallam et al reported national data on music service participation by ethnic group. Their study showed that, whilst $73 \%$ of music service pupils in 2004-05 were white, 'substantial proportions of ethnic minority groups' (2005: 9) also received tuition. Two years later, 
the national proportion of Key Stage (KS) 1 and 2 music service participants from Black, Asian and minority ethnic (BAME) backgrounds was between 28 and $30 \%$, overtaking the proportion in the school population as a whole (Hallam et al, 2007).

Further opportunities accompanied the introduction of the charity Youth Music's Endangered Species scheme in May 2004 (Bond, 2006). This provided funding to music services who wished to purchase stocks of instruments considered to be at risk of 'dying out' due to low take-up by young players. The instruments included were bassoon, oboe, French horn, trombone, tuba (including the euphonium), baritone horn and double bass. In total, 89 services received funding for over 2,100 instruments under the scheme, representing a total investment of $£ 1.2 \mathrm{million}$. Although separate from the MSF, many music services nonetheless made use of instruments purchased via the Endangered Species scheme to support ongoing schemes to broaden access to tuition (Hallam et al, 2005).

Hallam et al (2005) found that by 2004-05 just over two thirds of music services had policies on fee remission linked to free school meal eligibility whereas only a few music services had clear remission policies five years before. The government's introduction of a 'free school meals deprivation factor' (HC Hansard, 2001, Col. $274 \mathrm{~W}$ ) as part of MSF allocation methodology from 2001 offered further evidence of its wish to see access to instrumental music provision extended to pupils from backgrounds regarded as economically deprived. By 2004/05 12\% of pupils receiving music service tuition were found to be eligible for free school meals (FSM) by Hallam et al (2005). However, the figure was unchanged two years later, despite prevailing national figures for FSM eligibility of between $15.9 \%$ and $16.9 \%$. This prompted a notably more pessimistic comment in Hallam et al's follow-up survey: 'Music Services are still not reaching a fully representative sample of those receiving free school meals' (2007: 9).

Yet parents who did not qualify for remission faced further rises in tuition fees. According to Rogers (2005), the average hourly fee for local authority instrumental tuition passed on to parents in 2004 was $£ 25$, up by over $30 \%$ from $£ 19$ in 2002 . Thus, many parents would have inevitably faced a choice of whether to stick with the local authority music service or to instead purchase instrumental tuition privately. The 
costs may have been equivalent in many cases: the Incorporated Society of Musicians' recommended hourly rates for individual private tuition that year were between $£ 22.11$ and $£ 34.86$ (ISM, 2004). However, parents might well have regarded music service tuition as offing extra benefits, including access to free or low-cost instrument loans and ensemble opportunities, and tuition offered at their children's school within the school day. Some parents may even have mixed and matched private tuition with specific aspects of music service provision such as area youth ensembles. Here there are parallels with the so-called 'state until 8' practice whereby some UK parents are known to transfer children from state-funded primary schools to private education at the age of eight, thereby saving as much as a third on an all-private education (Killik, 2015; Warwick-Ching, 2017). A potential attraction of the local authority option was that MSF subsidy was likely to have reduced some of the true costs of the available services (Ofsted, 2003); by 2004/05 parental fees still only covered an average of $16 \%$ of service costs (Hallam et al, 2005). Access to rarer, more expensive instruments such as those funded by the Endangered Species Scheme- together with subsidised tuition on them in some cases-may have also added to the appeal of music service tuition in this period (Hallam et al, 2005; Widdison, 2009).

No comprehensive socio-economic data on instrumental learners is available for the period of time in which the MSF operated and so, beyond the use of FSM eligibility as a proxy indicator, accurate, national assessments of take-up by social grade are difficult. On the one hand, the media occasionally painted humorous pictures of wellhealed, middle-class North London parents making the most of their local authority's MSF-subsidised tuition (e.g. Morrison, 2000; Martin, 2004). On the other, Hallam et al (2005) felt able to conclude that:

the figures contradict the view that Music Services only cater for white middle class pupils and indicate that substantial proportions of children from minority ethnic groups, eligible for free school meals... do learn to play an instrument (2005: 9).

Put another way, it is conceivable that groups of similarly well-informed, more affluent middle-class parents were optimally placed to respond to official encouragements to act as educational consumers. In Bourdieu's terms, parents with greater levels of capital and a better 'feel for the game' (1990: 66) associated with 
this recently-colonised field may have surmised that MSF-subsidised music service provision offered the most cost-effective means of providing their children with highquality instrumental tuition. Conversely, the stall in the growth of participants from families eligible for FSM by 2007 suggests that children of parents with fewer capital endowments, less market acumen and less practical ability to overcome remaining, hidden barriers to this tuition might have continued to miss out in disproportionate numbers, despite the original intentions for the MSF.

Research into extra-curricular music activity as a means of achieving 'social closure' has been inconclusive. On the one hand, evidence from South Korea (Kim \& Kim, 2013) and Singapore (Tan, 2017) pointed to a link between parent-funded extracurricular activities such as instrumental lessons and a middle-class aspiration for social closure, achieved via admittance to higher-status schools as a result of enhanced cultural capital. Yet on the other hand, evidence from the USA (DiMaggio and Bryson, 1995) and France (Coulangeon, 2018) has suggested that parental enthusiasm for children's engagement with such extra-curricular activities is diffused across social groups and related more strongly to familial educational background. Therefore, in the remainder of paper, Connell's notion of the neo-liberal parent, together with two further Bourdieusian-influenced concepts, are used to illuminate these issues as they pertain to the take-up of, and persistence with, extra-curricular instrumental tuition within one case study local authority in England.

\section{Music education and the neo-liberal parent}

Connell $(2008 ; 2011)$ argues that family life cannot remain immune from the general imposition of neo-liberal educational policy:

Neo-liberal regimes, rejecting the principle of universal public education, subsidising private schooling and childcare, and corporatizing public institutions, have created pressures on parents to operate as investors and consumers in a market, competitively maximising family gains from education (Connell, 2011: 52).

Consequently, 'being a good parent means buying the best services for one's own children' (2011:56). According to Connell, this results in a class-based re-ordering of parent-child relations: 
Middle-class parents, with more money and with educational know-how, tend to respond in the way desired by neo-liberal policy, actively planning educational careers for their children, scanning the market and choosing schools that offer a more academic curriculum (2008: 187-188).

In contrast, Connell observes, 'working-class families are wedged away from the new mechanisms of educational advantage' (2011: 56).

This class-based dichotomy resonates in many ways with Lareau's (2002) concept of concerted cultivation, an observed tendency of middle-class American parents in her research to seek out curricular and extra-curricular opportunities perceived to have beneficial social impacts on their children. According to Lareau, the strategies adopted by these parents differed markedly from those parents from working class and poorer backgrounds. The latter groups were less likely to enrol their children in organised activities and more likely to emphasise, in Lareau's terms, the 'accomplishment of natural growth' (2002: 748). Ilari's (2013; 2016; 2018) international fieldwork systematically considers the concept of 'concerted cultivation' in relation to music education. Whilst she identifies significant cultural variation, Illari nonetheless observes that social class continues to exert an influence in musical childhoods across the world, particularly on the extent of parental involvement. Ilari proposes the existence of 'musical parenting' as 'a group of music-related cognitions, values, and behaviours of parents in relationship to their children' with 'clear implications for music teaching and learning' (2018: 46). Common dispositions include possessing musical instruments at home, preparedness to purchase further instruments as necessary and a tendency to take children to hear live concerts.

It seems possible that in certain cases these 'neoliberal' and 'musical' parenting strategies might cohere, shaping some parents' habitus in powerful ways. As Bourdieu puts it, 'those sections which are richest in cultural capital are more inclined to invest in their children's education at the same time as in cultural practices liable to maintain and increase their specific rarity' (1977: 502). Conversely, some involved in implementing the Endangered Species scheme cited a lack of parental awareness of instrumental diversity as a reason for reduced take-up of less prominent orchestral instruments (e.g. Clark, 2006). More generally, parental awareness and support were identified as crucial to this scheme's success (Bond, 2005). In Bourdieusian terms, 
the presence of musical instruments in the home are examples of enhanced objectified cultural capital, whilst the ability to play them is a form of embodied cultural capital (Bieber, 1999). Some evidence of links between the presence of instruments in the home and greater familial educational and occupational status has emerged (e.g. Koustourakis et al, 2016) although other studies have been more equivocal (e.g. Marks et al, 2007).

According to Connell (2011), the neo-liberal reframing of parenthood as an investment opportunity motivates more active involvement in the formal and informal education of one's children. This observation echoes the work of others in the Bourdieusian tradition who have noted the social reproductive potential of homeschool synergies. Coleman defined 'resource boosters' to describe academic advantages afforded to children who 'experience favourable conditions at home and school' (1990: 4). Developing the concept through further empirical work, Parcel and Dufur highlight the potential for interactive effects when greater human capital at home (e.g. parents with higher educational achievement themselves) is combined with greater social capital at school (e.g. schools with fewer 'social problems' (2001: 887 ) such as absenteeism, crime and higher-risk pupil behaviour). Research suggests that musical activity can be readily assimilated into these home-school synergies, potentially resulting in further advantageous musical, social and academic outcomes for certain groups (Costa-Giomi and Chappell, 2007; Horsley, 2015).

If we accept the premise that some neo-liberal parents may make a conscious decision to invest in their children through instrumental tuition, we might then ask what returns might be expected from sustaining these investments over time. In addition to potential opportunities to develop further social and cultural capital, considerable neuropsychological research evidence now indicates that sustained, intensive study of a musical instrument impacts on young people's neurological organisation and, consequently, on various aspects of other-than-musical cognitive development (Costa-Giomi, 2014). Much literature has dealt with the apparent associations with academic attainment in areas such as numeracy, literacy and language (Hallam, 2015), including findings known to have been influential on the Government at the time the MSF was introduced (Cox, 2010; Finney, 2011). Within the research, tuition durations of, on average, two years are frequently given as 
tipping points at which the various neurological, psychological, or cognitive impacts become clearly discernible. Thus, researchers and policy-makers should be not only concerned with which groups are best-placed to take-up instrumental tuition in the first place but also which are best placed to persist in this engagement for two years or longer.

\section{Introducing the case study local authority music service}

The case study local authority was situated within an urban area of England. Its area took in one of the largest, socio-economically and ethnically diverse towns in the region. Recent decades have witnessed the emergence of areas of significant financial and educational deprivation alongside others populated by more affluent workers, managers and freelancers. The diverse population exerts significant cultural influence and the town boasts a rich calendar of festivals, public events, and a large number of arts, cultural and heritage venues.

The authority received unparalleled levels of funding from the MSF for three reasons. Firstly, national allocations from the fund were partially matched to local authorities' own recent investments in their music services. It was a happy coincidence that the case study authority had made considerable investments in its service the previous financial year, precisely the period for which these matched MSF allocations were calculated. Secondly, the authority's position in the top quartile for FSM eligibility nationally meant it also benefited from further uplifts to its allocation. Thirdly, the case study's music service manager was well regarded for his local knowledge, persuasiveness and financial acumen. Thus, the service was well-placed to meet requirements that MSF applications should make strong cases for enhanced funding on the basis of equality of access, diversity of provision and collaboration with schools. As a result of these factors, the case study authority received an annual average of just over $£ 25$ for each pupil in its schools whilst the national per-pupil equivalent figure was less than $£ 9$ (HC Hansard, 2008; DCSF, 2009). Its music service expanded significantly, undergoing almost a six-fold increase in staff between 1997 and 2001. The authority sought to develop provision to be as diverse and accessible as possible, a commitment later recognised nationally (NMC, 2002). 
Unremitted parental fees for tuition remained at $£ 10$ per term until September 2002, rising to $£ 18$ by September 2004 . To put matters further in perspective, whilst unremitted parental fees increased again to $£ 30$ per term in September 2006, the unsubsidised per pupil cost to the authority of delivering a term of lessons was, by that time, $£ 120$. Fees included ensemble membership and access to extra-curricular music schools. Moreover, $100 \%$ fee remittance was offered to families in receipt of state benefits. Instruments were provided on free loan and an assisted purchase scheme enabled pupils to buy their own at reduced, VAT-exempt prices. Thanks to MSF subsidy, the range of provision was also significantly increased to embrace not only pop and rock instrumentation, but also non-Western traditions reflecting the authority's large South Asian, Black-Caribbean and Irish communities. Moreover, the service received funds to purchase additional stocks of all eight instruments covered by the Endangered Species scheme. Staff arranged demonstration concerts and ensemble days to promote these instruments in local schools.

The authority's wide socio-economic variance and rich cultural heritage, combined with propitious MSF allocation and pro-active commitments towards diversity and accessibility, marked it out as a 'deviant' (George and Bennett, 2005; 111), idiographic case (Mitchell, 2006), through which the practical outcomes of central government's intentions for the MSF could be studied at a local level. Put in simple terms, the case study was envisaged as a means of testing the hypothesis that 'if this won't work here', it may not work anywhere'.

The case study music service consented to make available its database of 6,350 pupil records covering September 2003 to November 2010, anonymised through the removal of pupil names. Of these, 4,451 were associated with primary school learners (aged eight ${ }^{1}$ to eleven) living within the case study borough and this subset is the focus below. A small number of participant records were excluded due to incomplete postcodes, dates of birth or school attendance data. $60.7 \%$ of the primary-aged pupils were female and $39.3 \%$ male, a sex ratio almost identical to comparable data offered by contemporaneous, national studies (Ofsted, 2004;

\footnotetext{
${ }^{1}$ It was the case study music service's policy to recruit pupils aged eight and above.
} 
Hallam et al, 2005) as well as more recent figures for music education hub engagement (Fautley, 2017). The continuing presence of such a marked sex bias in participation in instrumental music tuition is, of course, a matter of serious concern for researchers and policy-makers alike. However, preliminary spatial analysis (see Moran's / tests below) identified very little geographical variation or clustering in this sex ratio over the case study area. Thus, given this study's focus on ecological variation in music service participation, this bias is noted but not pursued further in this particular article.

\section{Methods}

An ecological study design was employed to assess the extent to which aggregated measures of primary-aged children's take-up and persistence with case study music service instrumental tuition (termed participant variables) were associated with various, similarly-aggregated measures of deprivation, socio-economic and school factors (termed contextual variables). The various theoretical perspectives reviewed above highlight the joint salience of home and school environments and to the potential for active interplay between these sites. Therefore, analysis was undertaken in two distinct ways. Firstly, music service pupils were aggregated by the area in which they lived (the 'area-level' analysis). Secondly, they were aggregated on the basis of the primary school that they attended (the 'school-level' analysis).

At both the area and school levels, initial assessments of spatial clustering within the aggregated participant variables were conducted using Moran's / tests (Lloyd, 2010). Subsequently, Spearman's non-parametric correlation test was used to assess magnitudes of association between the participant and contextual variables. For practical purposes, the participant variables represented almost the entire idiographic sub-population. Therefore, traditional sample-based probability inferences were not appropriate to interpret results (Filho et al, 2003; Ellis and Steyn, 2013). Instead, Spearman's rho was interpreted as a measure of effect size (Maher, Markey \& Ebert-May, 2013) and the discussion below employs the descriptive terms for these sizes suggested by Cohen (1992) and Hopkins (2002). This said, the omission of incomplete or invalid records meant that the data were technically just short of representing an entire sub-population. Therefore, statistical insignificance is 
indicated where results were associated with $p$ values of $>0.05$. However, this should not be taken as a suggestion that the remaining results are necessarily generalisable beyond this idiographic case.

A recognised caveat regarding this study's reliance on aggregated data is the potential for conclusions to be influenced by the ecological fallacy (Saunders, 2014). Results reflect averaged factors associated with the aggregated groups and one cannot assume that individual-level correlations necessarily reflect correlations identified at the aggregated level. Similarly, causal inferences about the impact of one variable on another are problematic. Such assumptions and inferences are carefully avoided in the discussion which follows. Furthermore, these levels of aggregation represent the finest levels of resolution available for the majority of the contextual variables, and this may serve to limit effects of the fallacy (Hungerford et al, 2014; Asaria et al, 2017).

Yet it is also important to stress the merits of focusing analysis above the level of the individual, given that music services and, latterly, music education hubs, typically coordinate provision at area and school levels. In this sense, ecological studies offer the advantage of highlighting structural social-economic variation and the community-level impacts of this kind of strategic decision-making. These kinds of studies serve as a reminder that consideration should also being given to the equally-problematic individualistic (or atomistic) fallacy, where the experiences of individuals are taken as evidence of general effects (Pearce, 2000). Therefore, the aggregated analysis below is not intended as a substitute for individual-level analysis but is instead intended to offer insights into the group-level outcomes of provision targeted explicitly or implicitly at certain groups.

\section{Participant variables}

Instrumental tuition records were used to infer additional information about each primary school participant, such as the total time spent learning formally with the music service and the school(s) attended during periods of tuition. Pupils' postcodes were used to identify the Lower Level Super Output Area (LSOA) level in which they lived. LSOAs are the smallest spatial unit of resolution at which much socio- 
economic data is published. Typically, each LSOA in England has a population of c.1500 residents (ONS, 2010). The analysis involved three distinct participant variables, each calculated at both the area level and the school level.

\section{Measure of instrumental tuition take-up}

This measured the proportion of young people aged between eight and eleven who took up the opportunity of instrumental tuition from the case study local authority's music service. Within the area-level analysis, location quotients (St John and Richardson, 1996) were used to indicate tuition take-up. These gave an accurate representation of the proportion of young people in each LSOA who engaged with music service tuition for each of the 21 academic terms covered by the case study time period. The contextual data used as the necessary divisors within these calculations were drawn from Hallam et al (2005), the 2001 UK Census (UK Data Service, 2013) and the January 2005 School Census (DfES, 2005). Purves (2017) provides full details of the methodology used. The resulting termly location quotient scores for each LSOA were then averaged over the case study period.

Within the school-level analysis, tuition take-up was defined as the average number of eight- to eleven-year-old pupils at each primary school who received music service tuition each academic year between 2003 and 2010. It was expressed as a percentage of all similarly-aged pupils on each school's roll at the point of the January 2010 School Census (DfE, 2010). Data for a total of 4,383 pupils were included, a slightly smaller number than the area-level analysis due to the absence of valid dates of birth.

\section{The 'two years of tuition' and 'Endangered Species' measures}

The 'two years of tuition' measure was used to determine the proportion of music service pupils who persisted in their tuition. It was calculated as the percentage of all music service pupils living in a particular LSOA or attending a particular primary school who had completed two or more years of tuition during the period covered by the case study data. The measure of those learning Endangered Species 
instruments was similarly calculated as a percentage of all the total numbers receiving tuition on the eight instruments covered by this scheme.

\section{Contextual variables}

In themselves, many contextual factors are inherently qualitative, examples of what Clinton refers to as 'unobservable quantities of interest' (2004: 879). Therefore, pragmatic decisions were necessary to identify variables which would function as proxy representations of these factors as closely as possible. Aggregated variables relating to family social grade and household income were selected both on the basis of their alignment with Connell's neo-liberal parent concept and also to reflect very long-standing concerns regarding the associations between music service tuition and related demographic factors, such as ethnic background. Further variables were selected to respond to additional long-standing concerns regarding various hidden barriers to accessing this tuition, e.g. access to vehicles, and perceptions of home conditions and local levels of crime (e.g. Cleave and Dust, 1989; Artservice, 2005). Finally, groups of variables were selected to reflect the twin components of the resource booster concept, i.e. favourable conditions at home (such as levels of local educational attainment and professional links with arts and culture) and at school (such as average KS2 results and rates of unauthorised absence).

Despite great care in the selection of these proxy variables, it is acknowledged that some may reflect underlying factors better than others. As such there is potential for misclassification bias (Hungerford et al, 2014). For instance, some of the most recent literature in this area encourages researchers to move beyond simple binary-based social class distinctions and to embrace greater intersectional variation (e.g. Vincent, 2017) and this was not possible here. It is also possible that the related modifiable areal unit problem may have impacted on the area level analysis, although related geospatial tests on a superset of the same data have confirmed a good degree of resilience to this (see Purves, 2017). 
Contextual variables for the area level analysis were drawn from three Government datasets at LSOA resolution. Firstly, three constituent measures of the 2010 English Indices of Deprivation (IMD) were used (MHCLG, 2011; McLennan et al, 2011). These included the Income Deprivation Domain score, where higher values indicate LSOAs with greater average levels of income deprivation, and the Crime and Disorder score, in which higher values indicate greater prevalence of reported crime. Also included was the Children and Young People Subdomain which provides a composite indication of educational deprivation. Higher scores represent increased local prevalence of school absence, drop-out and low educational attainment.

Contextual variables derived from 2001 UK Census data (UK Data Service, 2013) included the percentages of individuals in each LSOA in possession of higher education qualifications, from Black, Asian and minority ethnic backgrounds and those working in the areas of culture, media and sport. With regards to the last of these, it would have been preferable to obtain figures reflecting only the local arts and culture workforce but this was not possible due to UK census categorisations. Also derived from the census was the percentage of households with access to a vehicle and an estimation of the percentage of an LSOA's population comprising individuals falling within the Market Research Society's A, B and C1 social grade classifications (MRS, 2006). This measure includes those conventionally deemed middle class, on the basis of careers in technical, managerial and professional fields. Finally, the housing quality score was taken from the 2009 Local Index of Child WellBeing (Bradshaw et al, 2009). This indicates the impact of accommodation challenges on young people; data on overcrowding, sharing, homelessness and an absence of central heating are all factored in. Higher values indicate greater prevalence of poorer housing within an LSOA.

\section{School-level contextual variables}

Three school-level contextual variables were derived from the January 2010 School Census (DfE, 2010). The first indicated the percentage of a school's pupils eligible for FSM, whilst the second was the percentage of pupils from BAME backgrounds. The third indicated the percentage of pupils with English as an additional language (EAL). The remaining two contextual measures averaged annual school performance and absence data for 2003 to 2010 (DfE, 2015). The first of these was 
the mean End of Key Stage 2 Average Points Scores (APS) for maths, English and Science (McLennan et al, 2011) for each school over this period. The second averaged annual unauthorised absence figures for each school.

\section{Results and discussion}

Figure 1 displays the area-level take-up data as a choropleth (St John and Richardson, 1996). Darker shading is indicative of LSOAs with greater tuition take-up and the level of spatial clustering is clearly evident. This said, it should be noted that $79 \%$ of the case study LSOAs have a take-up location quotient of greater than 1.0, indicating above-national levels of participation in local authority instrumental tuition and attesting to the local authority's commitments towards diversity and accessibility. Figure 1 also displays the general locations of schools with tuition take-up at the median level or higher. The proximity of these schools to LSOAs with particularly high levels of take-up should be noted. Moran's I tests confirm reasonably high levels of spatial autocorrelation for the area take-up $(I=0.42)$ and for the school level take-up $(I=0.29)$. Only slightly less spatial autocorrelation was present in the proportions of music service pupils learning Endangered Species instruments at the area level $(I=0.28)$ and at the school level $(I=0.25)$. Again, distinct clusters of areas and schools where these instruments were more prominent can be seen in Figure 2. On the other hand, there was no spatial clustering when it came to the two years of tuition measure. At the area level, Moran's I was $0.03(p>0.05)$ whilst at the school level it was $0.10(p>0.1)$. Moreover, as noted above, Moran's / scores for differences in tuition take-up by sex were also very low at both area $(I=-0.03, p>0.1)$ and school levels $(I=0.01, p>0.1)$.

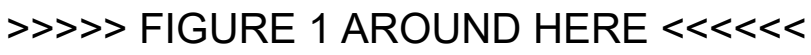

>>>> FIGURE 1 CAPTION $<<<<<~$

Figure 1 Choropleth map showing the level of tuition take-up in each LSOA within the case study local authority. Take-up is expressed as a location quotient, so that lighter shading indicates below-national levels of participation (values $<1$ ), whilst increasingly darker shading indicates above-national levels (values of $>1$ ). The map also indicates the general locations (bounded by ellipses) of schools with tuition take-up above the median level for all primary schools in the authority. Contains 
National Statistics data (C) Crown copyright and database right 2016; Contains OS data (C) Crown copyright (2016).

>>>> FIGURE 1 CAPTION ENDS $<<<<<<~$

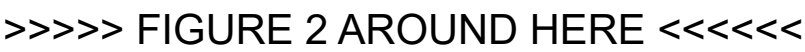

>>>> FIGURE 2 CAPTION $<<<<<<~$

Figure 2 Choropleth map showing the percentage of music service pupils living in each LSOA who learning an Endangered Species instrument. The map also indicates the general locations (bounded by ellipses) of schools where the percentage of Endangered Species learners was above the median for all primary schools in the authority. Contains National Statistics data (C) Crown copyright and database right 2016; Contains OS data @ Crown copyright (2016).

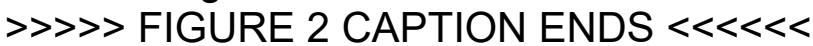

Table 1 provides area-level findings whilst Table 2 provides school-level findings. Results are given the form of correlation matrices in order to highlight not only the effect sizes between participant and contextual variables but also between the various contextual variables themselves. 
Table 1: Spearman Correlation Matrix for participant and contextual variables aggregated at the level of 121 lower-level super output areas (LSOAs) inhabited by case study music service pupils between 2003 and 2010. Correlations with $p$ values of $>0.05$ are shown in italics, though note the caveat regarding these values in the text.

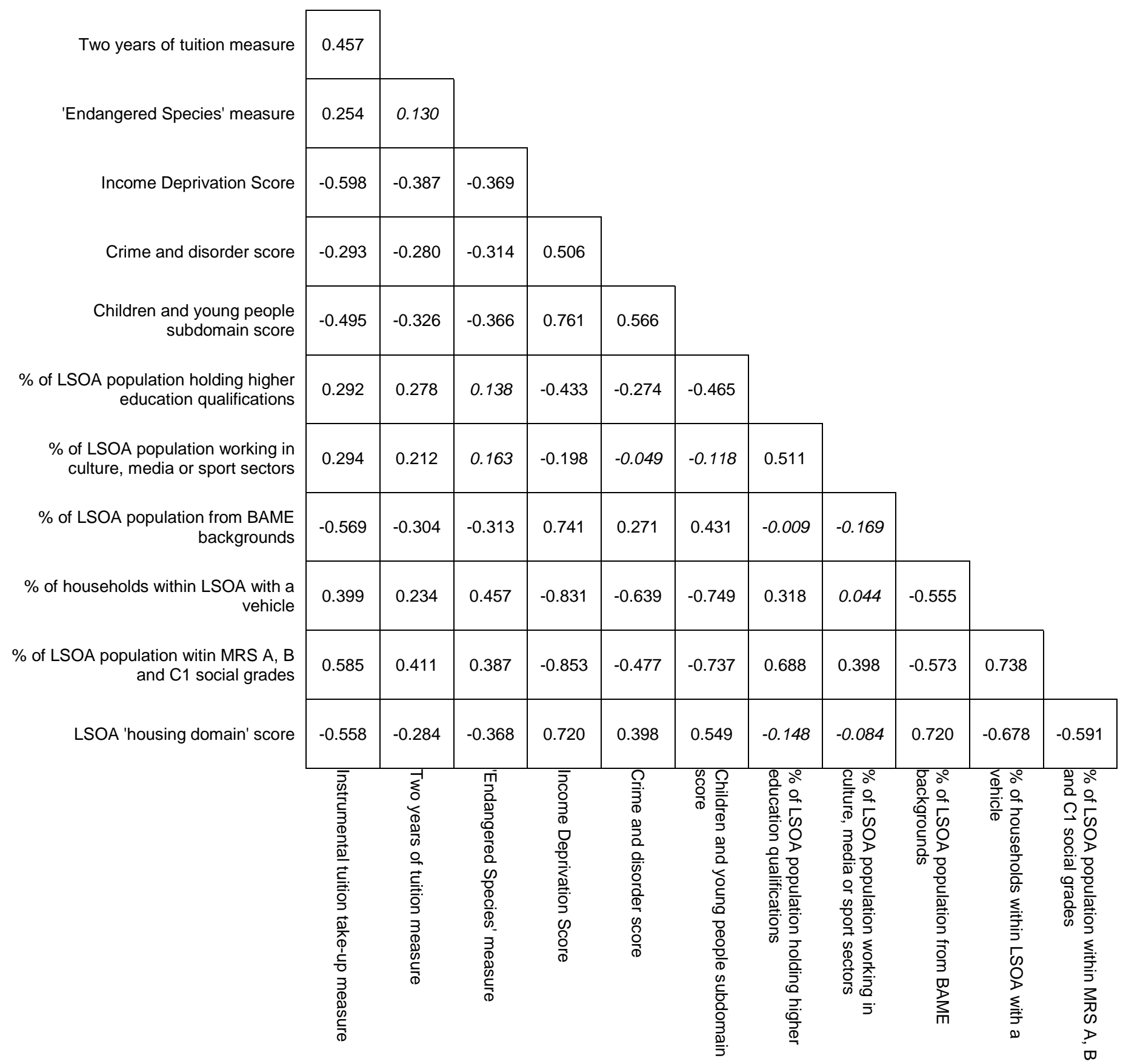


Table 2: Spearman Correlation Matrix for participant and contextual variables aggregated at the level of 37 primary schools attended by case study music service pupils between 2003 and 2010. Correlations with $p$ values of $>0.05$ are shown in italics, though note the caveat regarding these values in the text.

\begin{tabular}{|c|c|c|c|c|c|c|c|}
\hline Two years of tuition measure & .573 & & & & & & \\
\hline $\begin{array}{r}\text { 'Endangered Species' } \\
\text { measure }\end{array}$ & .526 & .554 & & & & & \\
\hline$\%$ of pupils eligible for FSM & -.557 & -.624 & -.524 & & & & \\
\hline $\begin{array}{r}\% \text { of pupils from BAME } \\
\text { backgrounds }\end{array}$ & -.754 & -.466 & -.512 & .395 & & & \\
\hline$\%$ of pupils with EAL & -.788 & -.449 & -.468 & .418 & .921 & & \\
\hline Mean Key Stage 2 APS & .761 & .685 & .635 & -.845 & -.558 & -.563 & \\
\hline \multirow{2}{*}{$\begin{array}{r}\text { Average \% of unauthorised } \\
\text { absence }\end{array}$} & -.403 & -.260 & -.243 & .325 & .351 & .282 & -.416 \\
\hline & 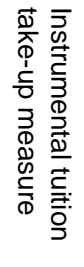 & 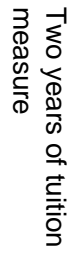 & 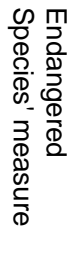 & 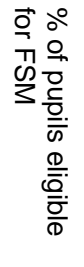 & 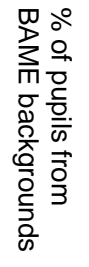 & 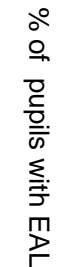 & 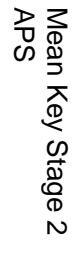 \\
\hline
\end{tabular}

With regards to the neoliberal parent concept, and notwithstanding the overall high number of LSOAs with above-national levels of participation, it is clear that tuition take-up was considerably stronger in areas characterised by lower levels of income deprivation and populated by greater numbers of people in the ABC1 bracket. Moreover, these same two area variables formed the strongest correlations with the numbers of local young people persisting with tuition for two years or longer. They were also amongst the strongest correlators with Endangered Species instrument take-up. The general alignment between average area-level social grade and income level is suggested by the very large negative correlation between them (-.853). Yet the prominence of further large correlations between many of the contextual variables in Table 1 suggests that economic capital may only be one of multiple, interrelated factors associated with area-level tuition take-up and persistence. 
Moreover, it should be remembered that termly fees were amongst the lowest charged by any music service and that $100 \%$ remission was available to families in receipt of state benefits.

Perhaps most notable is the large negative correlation between tuition take-up and the size of the local non-white British population, and the associated large correlations between the size of this population, level of income deprivation and ABC1 demographic. This is a very significant finding, particularly when considered alongside the medium-sized correlations for BAME population size and the other two participant variables. Internal case study authority documents reported that, in 200506, just over $50 \%$ of tuition take-up was amongst pupils from Black, Asian and other minority ethnic backgrounds. This contrasted with equivalent national figures of between $27 \%$ and $30 \%$ reported by Hallam et al (2005) for approximately the same period. In line with both its stated principles and the MSF objectives, the case study music service was successful in reaching an above average proportion of young people from these backgrounds. Yet the correlations in Table 1 suggest that such a pro-active emphasis may still not have been enough to raise and maintain participation amongst these groups in areas more strongly associated with greater income deprivation. The large negative correlation between average local housing quality and BAME population size offers further food for thought, not least because official reports of the time noted that some sections of the authority's minority ethnic communities were more likely to be living in poorer quality housing stock.

Connell (2011: 56) argued that parents on lower incomes may be 'wedged away' from educational advantage and yet we know that MSF funding allowed for low fees and comprehensive remission within the case study local authority. This may point to the continuing salience of so-called hidden barriers. Table 1 confirms that some of these, including levels of average local housing deprivation and vehicle ownership resulted in medium strength correlations with local take-up. A small correlation was also recorded with local levels of crime and disorder. There were also mediumstrength correlations between these same contextual variables and the proportions of young people taking up Endangered Species instruments. These offer some support for professional concerns that larger and heavier instruments were less 
popular partly due to the challenges of storage and transportation (Bond, 2005; Clark, 2006).

However, area levels of housing quality and vehicle ownership also produce very large correlations with income deprivation. This highlights the possibility that, whilst income deprivation may have been addressed to a certain extent by low fees and remission, costs associated with the day-to-day viability of this tuition may still have been factors in some areas. Further evidence for this is found at the school-level, where a large correlation was witnessed between FSM eligibility and the proportion of pupils sustaining tuition for two years or more.

At the school level, there were strongly negative correlations between tuition take-up and both the proportions of pupils from BAME backgrounds and those with EAL. The reasons may be similar to those discussed above in relation to the area level, although the correlation between income deprivation (as evidenced by FSM eligibility) and BAME population size is weaker in this case. Yet the proportions of pupils from BAME and EAL backgrounds (which themselves share an almost perfect correlation) both have large negative associations with mean APS. These reflect contemporary efforts within the case study authority to raise the educational achievement of certain minority ethnic groups and pre-empt discussion below regarding parallel links between educational achievement and certain forms of cultural capital. More recent evidence from very ethnically diverse communities (Creech et al, 2016) points to the need for schools to ensure that all parents receive explicit information on the full range of musical activities available to their children, thereby reducing the influence of unexplored assumptions about what might already be known or not known about the benefits of participation within different social groups.

Giving credence to Coleman's resource booster concept, Table 1 shows a very large correlation between area levels of income deprivation and educational deprivation (.761). At the school level an even larger correlation occurs between FSM eligibility and mean APS. At both levels, the contextual variables relating to income and educational deprivation draw on common data relating to state benefits take-up and average KS2 points scores so, to an extent, one is observing the same relationship. 
Table 2 confirms that FSM eligibility and mean APS were the strongest correlators with the Endangered Species and two-years of tuition measures. School absence, regarded by Parcel and Dufur (2001) as one marker of a school's social capital, correlated negatively with tuition take-up at the medium level but was less strongly associated with the other two predictor variables.

Taken as a whole, these findings do highlight a potential link between groups of case study pupils well-placed to achieve academically and those who were (a) more likely to take-up opportunities to learn instruments, including lesser-known so-called, endangered examples, and (b) well-placed to continue with instrumental tuition for a sustained period. Thus, there are grounds to conclude that the definition of resource boosters as favourable conditions at home and at school as the basis for academic achievement might also extend to instrumental tuition in this case. This supports conclusions by Koustourakis et al (2016) regarding the influence of cultural capitalas manifested by various musical activities and the presence of musical instruments in the home-on parents' educational aspirations for their children. It also raises the possibility that the habitus of some parents and teachers may come to accommodate the existence of these boosters, albeit doxically. Such a state of affairs would thus be 'perceived not as arbitrary, that is, as one possible order among others, but as a selfevident and natural order' (Bourdieu, 1977: 166). On the other hand, the relationship with the numbers of local people involved in culture, media and sport occupations is more difficult to interpret, given the lower correlation magnitudes for this variable across the board. However, the variety of professions included in this contextual variable highlights the potential for miscategorisation bias.

Overall, the various effects reported in Tables 1 and 2 confirm that primary-aged pupils' take-up and perseverance with music service instrumental tuition at both aggregated levels were embedded within a complex ecology of factors. Whilst some of these appear less correlated with take-up and persistence in themselves, consistently stronger effects between them and contextual variables relating to either social grade, income deprivation and/or ethnicity suggest the demographic profiles of areas and schools may be at the centre of this complex ecology. As a result, some groups may be better-placed than others to overcome the associated barriers to 
engagement with instrumental tuition even in situations where resources and commitments have been secured specifically to reduce these.

At the area level, the contextual variables correlated more strongly overall with the tuition take-up and Endangered Species measures than with the two years of tuition measure. This may be due partly to the choice of contextual variables. However, it may also indicate that in situations where groups of instrumental learners were able to overcome the barriers to initial participation discussed above, there exists a strong motivation to persist with tuition even in the face of considerable financial, time and logistical costs. This may be one reason why there was more spatial clustering in the tuition take-up and Endangered Species data and less in the two years of tuition data. I.e. whilst take-up and instrument choice were both more strongly associated with prevailing areal patterns of socio-economic advantage/deprivation and certain forms of cultural capital, individual families and learners' commitment to persisting with tuition weakened the influence of these factors as time went on. Likewise, some of the parents in Ilari's research aspired to provide the kinds of rich musical childhoods associated with middle class homes 'even if this represented a huge commitment in terms of time and money' (2016: 103).

These results offer evidence that, at both the area and school levels of this case study, many aspects of tuition take-up, persistence and instrument choice aligned with Connell's neo-liberal parenting concept. However, a limitation of the study design is that is not possible to identify the direction(s) in which the various factors exerted an influence and it is therefore harder to infer further conclusions on the basis of Lareau's (2002: 749) twin concepts of 'concerted cultivation' versus 'emerging sense of constraint'. Specifically, it is not clear whether more affluent, middle-class groups were taking up and sustaining instrumental tuition in greater numbers, whether less affluent groups were doing so in smaller numbers, or whether it was a structural combination of both. Therefore, the extent to which this state of events reflects a concerted effort towards social closure by certain social groups remains uncertain. All the same, it is clear that within this idiographic and deviant case, where engagement was well above national averages overall, instrumental tuition was still taken-up and sustained more effectively in certain areas and schools than others. This conclusion has implications for those planning similar kinds of 
provision, particularly in less propitious circumstances than those of the case study local authority.

\section{Conclusion and implications}

The case study findings suggest that low tuition fees, comprehensive remission policies and broadened stylistic diversity in provision were a strong foundation for increased access and participation in local authority instrumental tuition. However, in themselves, they may still not have been enough overcome area- and school-level variation in socio-economic profile, ethnic background and educational attainment.

Subsequently, it is possible that the 'boost' offered favourable conditions both at home and at school may help to propel individuals towards the most advanced stages of musical education, a situation with notable parallels in elite sport. For instance, $24 \%$ of the 2016 British Olympic team were privately educated (Woolcock, 2016). Figures for $2012 / 13$ show that an identical percentage of students at five of the UK's nine specialist music conservatoires also attended private schools (Scharff, 2015). By contrast, opposed only $7 \%$ of general school population were educated privately in this period.

With the evolution of most local authority music services into lead organisations for their local music education hubs, complex models of provision have emerged, including schemes founded upon a hub-accredited yet self-employed teaching workforce (Widdison et al, 2017). This has blurred even further the boundaries between tuition offered as part of the school day, as part of extra-curricular or community-based provision and through hub-facilitated, yet privately-made, arrangements between teachers and parents. In some cases, the same teaching personnel may be involved in all three, their contractual arrangements with the various stakeholders shifting accordingly. The neoliberal colonisation of the local authority music field has thus continued.

In such complex circumstances, there is once again the potential, at least, for those social groups with a stronger feel for the neo-liberal game, greater capital endowments and greater understanding of the possible extrinsic benefits to 
maximise the potential of the available opportunities. It is vital, then, that hubs retain centralised administrative and leadership teams who can develop strategy, maintain centralised resources, act as sources of guidance and support and-perhaps most importantly of all-pro-actively monitor levels of take-up and persistence across the areas served. Primary school music coordinators and senior management need to do likewise. They should remember that hidden barriers may persist due to intersections with other prevailing socio-economic conditions, confounding even the best-intentioned participation and access strategies.

Similarly, the results also indicate that hub and school music leaders need to look beyond established patterns of area and school take-up, since these may have emerged as components of deep-seated ecologies of various, contextual factors. Active targeting of more diverse ethnic and linguistic groups, those associated with less affluent backgrounds and lower average levels of academic achievement may be required. Evidence from Creech et al (2016) suggested that orchestral education programmes inspired by the Venezuelan 'El Sistema' model (such as Sistema Scotland, Sistema England and In Harmony in the UK) have had success in engaging young people in instrumental learning who would not otherwise have had the opportunity. This is thought to be due in part to concerted efforts within many such programmes to target families regarded as being 'hard-to-reach' (Creech et al., 2016: 28).

Such targeting is likely to benefit from the provision of clear information regarding potential extrinsic benefits associated with long-term persistence with instrumental tuition, along with funding to reduce the perniciousness of remaining hidden barriers such as transport, home conditions and the location of rehearsal and teaching sites. There is a particular need for school and hub music educators to remain reflexive regarding their own, possibly-privileged positions within these kinds of ecologies when planning pupils' instrumental tuition opportunities. According to Hardy, a 'reflective habitus... at least partially ameliorates neoliberal and bureaucratic logics and is reflective of the field of teachers' work as a space of active, ongoing, collaborative, critical, student-focused teacher learning practices' (2010: 82). In particular, it would be wise to ensure that the negative influence of socio-economic factors and hidden barriers highlighted above are not taken for a lack of motivation to 
commence or persist with tuition. Similarly, consideration should be given to situations where perceptions of musical 'talent' and interest might in reality be founded on greater familial awareness of music and music-making. 


\section{References}

ABRSM (1994). Making music: the Associated Board review of the teaching, learning and playing of musical instruments in the United Kingdom. London: Associated Boards of the Royal Schools of Music.

ABRSM (1997). Making music 1997: the Associated Board review of the teaching, learning and playing of musical instruments in the United Kingdom. London: Associated Boards of the Royal Schools of Music.

ABRSM (2000). Making Music 2000. London: Associated Boards of the Royal Schools of Music.

Ainscow, M \& West, M (2006). Improving Urban Schools: Leadership and Collaboration, Maidenhead, Berkshire, Open University Press/McGraw-Hill Education (UK).

Annetts, D (2010). 'Fighting for the Future', Keynote Speech, Music Learning Live Conference, Manchester, Friday 26 February 2010. Available at: http://www.ism.org/images/uploads/files/ISM_Deborah_Annetts_speech_MLL_Feb_2010.pdf (Accessed: 29 November 2012).

Arnot, C (2004). 'Strings attached: the soaring costs of music tuition are putting instruments beyond the reach of many children', The Guardian, 7 December, p. 6.

Artservice (2005). Endangered Species Evaluation: Phase 2 Report. Hereford: Artservice.

Asaria, M, Doran, T \& Cookson, R (2017). 'The costs of inequality: whole-population modelling study of lifetime inpatient hospital costs in the English National Health Service by level of neighbourhood deprivation', Journal of Epidemiology \& Community Health 70(10)

Bieber, J.P. (1999). 'Cultural Capital as an Interpretative Framework for Faculty Life', in J.C. Smart (ed.), Higher Education: Handbook of Theory and Research Volume XIV, Edison, New Jersey: Agathon Press, pp. 367-397.

Blunkett, D (1998). 'Facing the music'. Times Educational Supplement, 22 May, p.13.

Bond, A. (2005). Endangered Species Evaluation Phase 2 Report. Hereford: Artservice.

Bond, A. (2006). Endangered Species Evaluation Survey 2006 for Youth Music. Hereford: Artservice.

Bonnett, M (1996). "New' Era Values and the Teacher-Pupil Relationship as a Form of the Poetic'. British Journal of Educational Studies, 44 (1), pp. 27-41.

Bourdieu, P. (1977). Outline of a theory of practice. Cambridge: Cambridge University Press.

Bourdieu, P. (1984). The Field of Cultural Production: Essays on Art and Literature. Columbia University Press.

Bourdieu, P. (1990). The Logic of Practice. California: Stanford University Press.

Bradshaw, J, Bloor, K, Huby, M, Rhodes, D, Sinclair, I, Gibbs, I, Noble, M, McLennan, D, \& Wilkinson, K (2009). Local Index of Child Well-Being: Summary Report. London: Department of Communities and Local Government. 
Clark, R. (2006). 'The oboe, French horn and tuba', Western Mail, 28 November, p. 13.

Cleave, S, \& Dust, K (1989). A sound start: the schools' instrumental music service. Windsor: NFER-Nelson.

Cohen, J (1992). 'A power primer', Psychological Bulletin. 112 (1): 155-159.

Coleman, JS (1990). Foundations of Social Theory. Harvard University Press.

Cooper, DJ (1985). 'Selection Procedures Used by Peripatetic Instrumental Teachers'. British Journal of Music Education, 2 (1), pp. 19-38.

Connell, R (2008). 'The Neo-liberal Parent and Schools', Our Schools, Our Selves, 18 (1), pp.175-193.

Connell, R (2011). Confronting Equality: Gender, Knowledge and Global Change. Cambridge: Polity Press.

Coopers \& Lybrand/MORI (1994). Review of instrumental music services. London: Incorporated Society of Musicians.

Costa-Giomi, E (1999). 'The Effects of Three Years of Piano Instruction on Children's Cognitive Development', Journal of Research in Music Education 47 (3), pp. 109-212.

Costa-Giomi, E \& Chappell, E (2007). 'Characteristics of Band Programs in a Large Urban School District: Diversity or Inequality?', Journal of Band Research 42(2): 1-97.

Costa-Giomi, E (2014). 'The Long-Term Effects of Childhood Music Instruction on Intelligence and General Cognitive Abilities'. Update: Applications of Research in Music Education 2014, pp. 1-7.

Coulangeon, P. (2018). 'The Impact of Participation in Extracurricular Activities on School Achievement of French Middle School Students: Human Capital and Cultural Capital Revisited', Social Forces 97(1): 55-90.

Cox, G (2002). Living music in schools, 1923-1999: studies in the history of music education in England. Aldershot: Ashgate.

Cox, G (2010). 'Britain: Towards 'a long overdue renaissance'?'. In G. Cox and R. Stevens (Eds.), The origins and foundations of music education: cross-cultural historical studies of music in compulsory schooling. London: Continuum, pp. 15-28.

Creech, A, Saunders, J, \& Welch, G (2016). Musical Pride: music education in plural communities. London: UCL Institute of Education.

Creech, A., González-Moreno, P., Lorenzino, L., Waitman, G., Sandoval, E. \& Fairbanks, S. (2016). El Sistema \& Sistema Inspired Programmes: a literature review. California: Sistema Global.

DCSF (2009). Annex C Standards Fund Allocations 2008-2011 - Updated March 2009 [Microsoft Excel Spreadsheet]. London: Department of Children, Schools and Families. Available at:

http://webarchive.nationalarchives.gov.uk/tna/+/teachernet.gov.uk/ doc/12227/Annex\%20C $\% 20$ Standards $\% 20$ Fund $\% 20$ Allocations $\% 202008-2011 \% 20-$

\%20Updated\%20March\%202009.xls (Accessed: 27 November 2011). 
Degé, F, Wehrum, S, Stark, R, \& Schwarzer, G (2011). 'The influence of two years of school music training in secondary school on visual and auditory memory'. European Journal of Developmental Psychology 8 (5), pp. 608-623.

DfEE (1998a). Fair Funding: Improving Delegation to Schools. London: Department for Education and Employment..

DfEE (1998b). Supplement to Circular 13/98: The Standards Fund 1999-2000. London: Department for Education and Employment.

DfES (2005). Schools and Pupils in England: January 2005 (Final) [Microsoft Excel Spreadsheet]. London: Department for Education and Skills. Available at: http://webarchive.nationalarchives.gov.uk/20120506053051/http://www.education.gov.uk/rsg ateway/DB/SFR/s000606/index.shtml

DfE (2010). Schools, pupils and their characteristics: January 2010 [Microsoft Excel Spreadsheet]. London: Department for Education. Available atL https://www.gov.uk/government/statistics/schools-pupils-and-their-characteristics-january$\underline{2010}$

DfE/DCMS (2011). The Importance of Music: a national plan for music education. London: Departments for Education and Culture, Media and Sport.

DfE (2015). School performance tables [archived website]. Available at: http://webarchive.nationalarchives.gov.uk/20150812113237/http://www.education.gov.uk/sch ools/performance/archive/

DiMaggio, D. \& Bryson, B. (1995). Americans' attitudes towards cultural diversity and cultural authority: culture wars, social closure, or multiple dimensions? General Social Survey Topical Reports series, No. 27. Chicago: National Opinion Research Center.

Durston, R (1993). 'Local Music Services'. YES: Yamaha Education Supplement, 15 (summer term).

Ellis, SM \& Steyn, HS (2003). 'Practical significance (effect sizes) versus or in combination with statistical significance (p-values)', Management Dynamics 12(4): 51-53.

Evans, JD (1996). Straightforward statistics for the behavioural sciences. Pacific Grove, CA: Brooks/Cole Publishing.

Exeter, DJ, Rodgers, S, \& Sabel, CE (2014). "'Whose data is it anyway?" The implications of putting small area-level health and social data online'. Health Policy 114 (1), pp. 88-96.

Fautley, M. \& Whittaker, A. (2017). Key Data on Music Education Hubs 2017. Birmingham: Birmingham City University.

Filho, DB, Paranhos, R, da Rocha, EC, Batista, M, Alexandre da Silva Jr., J, Santos, ML \& Marino, JG (2013). 'When is statistical significance not significant?', Brazilian Political Science Review 7(1): 31-55.

Finney, J (2011). Music Education in England, 1950-2010: the child-centred progressive tradition. Farnham: Ashgate.

George, AL and Bennett, A (2005). Case Studies and Theory Development in the Social 
Sciences, Cambridge, MA: MIT Press.

Hallam, S (1998). Instrumental teaching: a practical guide to better teaching and learning. Oxford: Heinemann.

Hallam, S, Rogers, L \& Creech, A (2005). Survey of Local Authority Music Services 2005. Nottingham: Department for Education and Skills.

Hallam, S, Creech, A, Rogers, L, \& Papageorgi, I (2007). Local Authority Music Services Provision for Key Stages 1 and 2 [Research Report DCSF-RR014]. London: Institute of Education, University of London/Department of Schools, Children and Families.

Hallam, D (2012). Music Education Grant 2011/2012 Report based on Local Authority data returns, May 2012. Available at:

http://www.dickhallam.co.uk/resources/National\%20Music\%20Education\%20Grant\%202012 \%20final.pdf (Accessed: 23 August 2012).

Hallam, S (2015). The Power of Music. London: International Music Education Research Centre/Music Education Council.

Hardy, I. (2010). 'Critiquing teacher professional development: teacher learning within the field of teachers' work', Critical Studies in Education, 51(1): 71-84.

Harris, N (2007). Education, Law and Diversity. Oxford: Hart.

HC Hansard (10 May 2001). Music Standards Fund (written answer). Vol. 368, Col. 274W.

HC Hansard (3 June 2003). Music Standards Fund (written answer). Vol. 406, Col. 219W.

HC Hansard (2008). PQ196428: Standards Fund Music Allocations 1999-2000 TO 20072008. Vol. 474, Col. 693W.

Hill, D \& Kumar, R (Eds.) (2012). 'Neoliberalism and its impacts', in D. Hill \& R. Kumar, Global Neoliberalism and Education and its Consequences. Abingdon: Routledge.

Hopkins, WG (2002). 'A Scale of Magnitudes for Effect Statistics', A New View of Statistics: Internet Society for Sport Science [Weblog] Available at: http://www.sportsci.org/resource/stats/effectmag.html (Accessed 7 June 2018).

Horsley, S. (2014). A Comparative Analysis of Neoliberal Education Reform and Music Education in England and Ontario, Canada, Unpublished Doctoral thesis, University of Western Ontario, Canada.

Horsley, S (2015). 'Facing the music: pursuing social justice through music education in a neoliberal world', in C. Benedict, P. Schmidt, G. Spruce, \& P. Woodford (eds.), The Oxford Handbook of Social Justice in Music Education. New York: OUP, pp. 62-77.

Hudson, C \& Lidström, A (2002). Local Education Policies: Comparing Sweden and Britain. Basingstoke: Palgrave.

Hungerford, D, Vivancos, R, French, N, Iturriza-Gomara, M \& Cunliffe, N (2014). 'Ecological assessment of the direct and indirect effects of routine rotavirus vaccination in Merseyside, UK using data from multiple health systems: a study protocol', BMJ Open 4: e006161. 
Ilari, B (2013). 'Concerted cultivation and music learning: Global issues and local variations', Research Studies in Music Education 35(2): 179-196.

Ilari, B (2016). 'Middle-Class Musical Childhoods: autonomy, concerted cultivation, and consumer culture', in B. Ilari \& S. Young (eds,), Children's Home Musical Experiences Across the World. Indiana: Indiana University Press.

Ilari, B (2018). 'Musical Parenting and Music Education: Integrating Research and Practice', Update: Applications of Research in Music Education 36(2): 42-52.

ISM (2004). Information Sheet 02/13: Private Tuition: Rates from 1 September 2004 Individual Tuition. London: Incorporated Society of Musicians. Retrieved from https://web.archive.org/web/20041222172056/https://www.ism.org/info/02_13.html (accessed 7th June 2018).

Killik (2015). Killik Private Education Index: A CEBR report for Killik \& Co. London: Killik Wealth Planning.

Kim, D.H. \& Kim, J.H. (2013). 'Emerging High-Status Track in South Korea: Social Capital Formation in the Social Contexts of Foreign Language and General High Schools', AsiaPacific Education Researcher 22(1): 33-44.

Kingston, $P$ (2006). 'A tragi-comedy, in several parts: A change in funding could rob thousands of children of the chance to learn an instrument at school', The Guardian, 17 January, p. 3.

Koustourakis, G., Asimaki, A., Spiliopoulou, G. (2016). 'Cultural Capital and Educational Expectations of Native and Immigrant Parents of Primary School Students: Qualitative Study'. International Journal of Sociology of Education, 5(3): 166-189.

Lareau, A (2002). 'Social Class and Childrearing in Black Families and White Families'. American Sociological Review, 67 (5): 747-776.

M2 Communications (2000). Children across England to have chance to play musical instrument; Jacqui Smith announces music funding [UK government press release]. 10 October. Available at:

http://go.galegroup.com/ps/i.do?id=GALE\%7CA65907978\&v=2.1\&u=luton\&it=r\&p=GPS\&sw Ew (Accessed 31 December 2012).

Marks, G. N. Cresswell, J. \& Ainley, J. (2006) 'Explaining socioeconomic inequalities in student achievement: The role of home and school factors', Educational Research and Evaluation, 12:2: 105-128.

Martin, A (2004). Class conscious - Andrew Martin envies his son's refined taste. New Statesman, 8th Nov 2004: 63.

Mahar, JM, Markey, JC \& Ebert-May, D (2013). 'The Other Half of the Story: Effect Size Analysis in Quantitative Research', CBE-Life Sciences Education 12: 345-351.

McLennan, D, Barnes, H, Noble, M, Davies, J, \& Garratt, E (2011). The English Indices of Deprivation 2010. London: Department for Communities and Local Government. Available at: https://www.gov.uk/government/uploads/system/uploads/attachment_data/file/6320/1870718 .pdf (Accessed: 3 April 2013).

Mitchell, JC (2006). Case and Situation Analysis. The Manchester School: Practice and 
Ethnographic Praxis in Anthropology. T. M. S. Evens and D. Handelman, Berghahn Books: 23-44.

MHCLG (2011). English indices of deprivation 2010. Ministry of Housing, Communities \& Local Government [https://www.gov.uk/government/statistics/english-indices-of-deprivation2010]

Morris, R (2000). 'Outlook', Libretto, March, inside front cover.

Morrison, R (2000). 'Why Elvis will never leave the auditorium', The Times (London), 20 April, p. 9. [Times2].

MRS (2006). Occupation Groupings: A Job Dictionary. London: The Market Research Society.

NACCCE (1999). All our futures: creativity, culture and education. Report to the Secretary of State for Education and Employment and the Secretary of State for Culture, Media and Sport. National Advisory Committee on Creative and Cultural Education.

NMC (2002). The National Music Council Local Education Authority Music Awards - Report 2002, National Music Council.

Ofsted (2003). Wiltshire LEA Music Service: Inspection Report - Autumn Term 2003. London: Ofsted.

Ofsted (2004). Provision of music services in 15 local education authorities. London: Ofsted. ONS (2010). National Statistics Postcode Directory 2010: User Guide v4. Hampshire, Office for National Statistics.

Parcel, T, \& Dufur, MJ (2001). 'Capital at home and at school: effects on student achievement', Social Forces 79 (3): 881-912.

Pearce, N (2000). 'The ecological fallacy strikes back', Journal of Epidemiology and Community Health 54: 326-327

Pill, M (2007). 'What rationales are driving neighbourhood governance initiatives in the US and the UK', "The Vital City": European Urban Research Association $10^{\text {th }}$ Anniversary Conference. University of Glasgow, 12-14 September. [Retrieved 23 November 2011 from: www.gla.ac.uk/media/media 33208 en.pdf].

PRS (1999). Musical instrument tuition in schools : findings of the 1998 survey. London: Performing Right Society.

Purves, R (2017). 'Music technology, education and maps: The use of geospatial technology and data to inform music education research'. Journal of Music, Technology and Education, 10 (1), 117-138.

Rainbow, B, \& Cox, G (2006). Music in educational thought and practice: a survey from 800 $B C$. Woodbridge: Boydell Press.

Rauscher, FH, \& Hinton, SC (2011). 'Music instruction and its diverse extra-musical benefits'. Music Perception, 29 (2), pp. 215-226. 
Richards, G \& Armstrong, F (2010). Teaching and Learning in Diverse and Inclusive Classrooms: Key Issues for New Teachers. Abingdon: Routledge.

Ridgeway, CG (2002). Orchestral training in the United Kingdom. Unpublished Doctoral thesis, City University, London.

Rogers, R (2005). The Music Manifesto Report No 1. London: DfES/DCMS.

Rogers, L., \& Hallam S. (2010). 'Music Services'. In S. Hallam \& A. Creech (Eds.), Music Education in the 21st Century in the United Kingdom: Achievements, analysis and aspirations. London: Institute of Education, pp. 279-294.

Saunders, C (2014). 'Ecological Studies: use with caution', British Journal of General Practice 64(619): 65-66.

Schellenberg, EG (2006). 'Long-Term Positive Associations Between Music Lessons and IQ'. Journal of Educational Psychology, 98 (2), pp. 457-468.

Schlaug, G, Forgeard, M, Zhu, L, Norton, A, Norton, A, \& Winner, E (2009). 'Training-induced Neuroplasticity in Young Children'. Annals of the New York Academy of Sciences, 1169, pp. 205-208.

Sharp, C (1991). When every note counts : the schools' instrumental music service in the 1990s. Slough: National Foundation for Educational Research in England and Wales.

Sharp, C (1995). Providing instrumental music tuition: a handbook for schools and services. Slough: National Foundation for Educational Research.

Smithers, R (1999). ' $£ 180 m$ boost for music education in schools', The Guardian, 28 January, p. 12.

St John, P. and Richardson, D. (1996), Methods of Presenting Fieldwork Data, Sheffield: Geographical Association.

Tan, C. (2017). 'Private Supplementary Tutoring and Parentocracy in Singapore', Interchange 48(4): 315-329.

UK Data Service (2013). 2001 Casweb: Aggregate Statistics Datasets for Super Output Area (SOA) Geography. [http://casweb.ukdataservice.ac.uk/]

Vincent, C. (2017) "The children have only got one education and you have to make sure it's a good one': parenting and parent-school relations in a neoliberal age', Gender and Education 29(5): 541-557.

Ward, D (1993). 'Peripatetic music: Variations on a theme. Pressures on spending have threatened the future of instrument teaching', The Guardian, 4 January, p.6.

Warwick-Ching, L. (2017). 'Pay attention at the back: 10 ways to save on school fees', Financial Times (London) 9 December: 8.

Widdison, I. K. (2009). The National Music Council / Music Education Council Music Awards 2009. London: National Music Council. 
Widdison, D, Barnard, D \& Walters, C (2017). 2017 Education Report: A review of the current provision of music education in England. London: Musicians' Union

Williamson, N (1998). 'Rattle Cry', Times Educational Supplement, 15th May (No 4272): C4.

Woodward, W (2000). 'Class gap in music lessons narrows', The Guardian, 4 July, p. 1.

Wright, D.C.H. (2013). The Associated Board of the Royal Schools of Music: A Social and Cultural History. Suffolk: Boydell. 


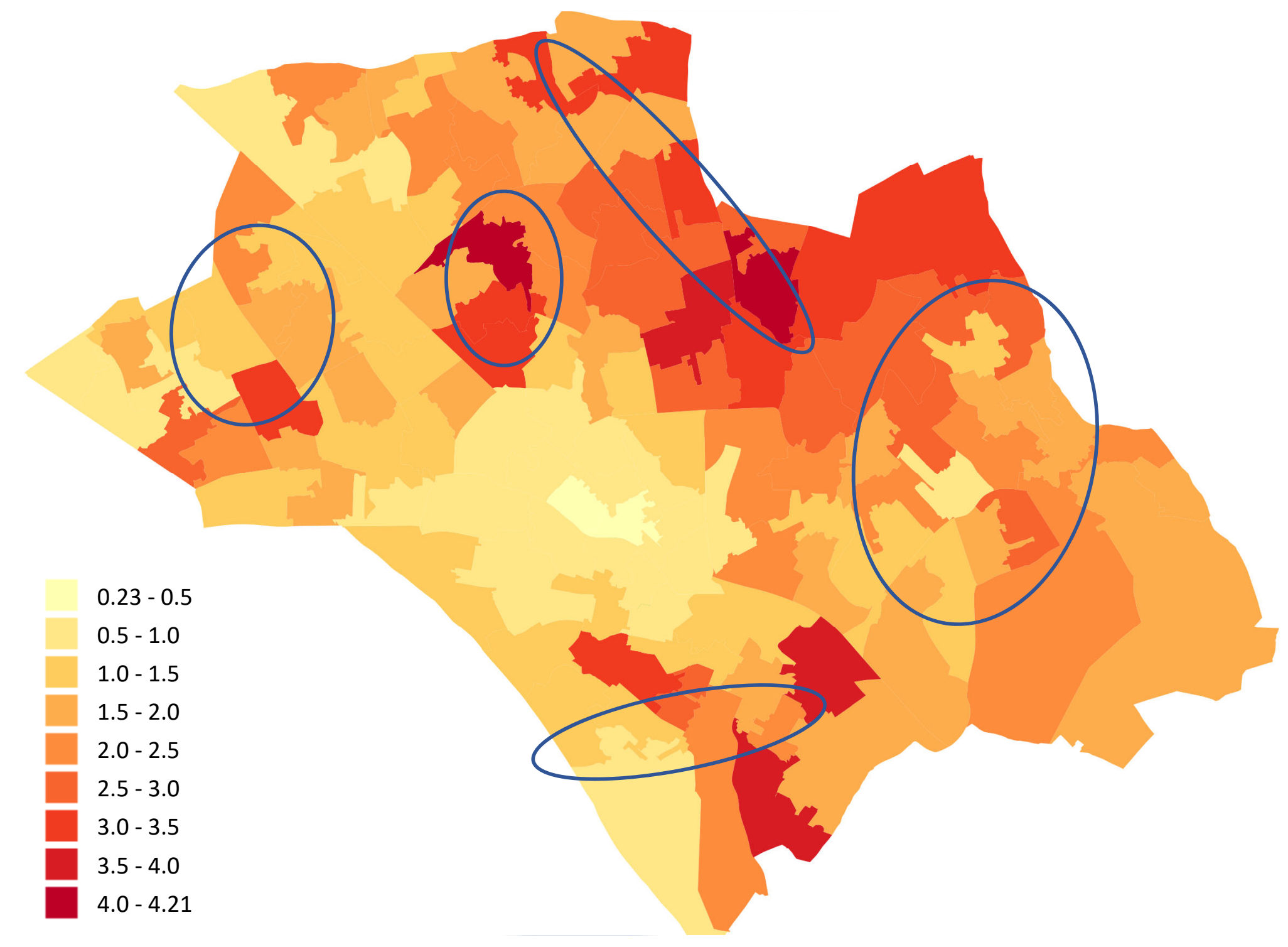




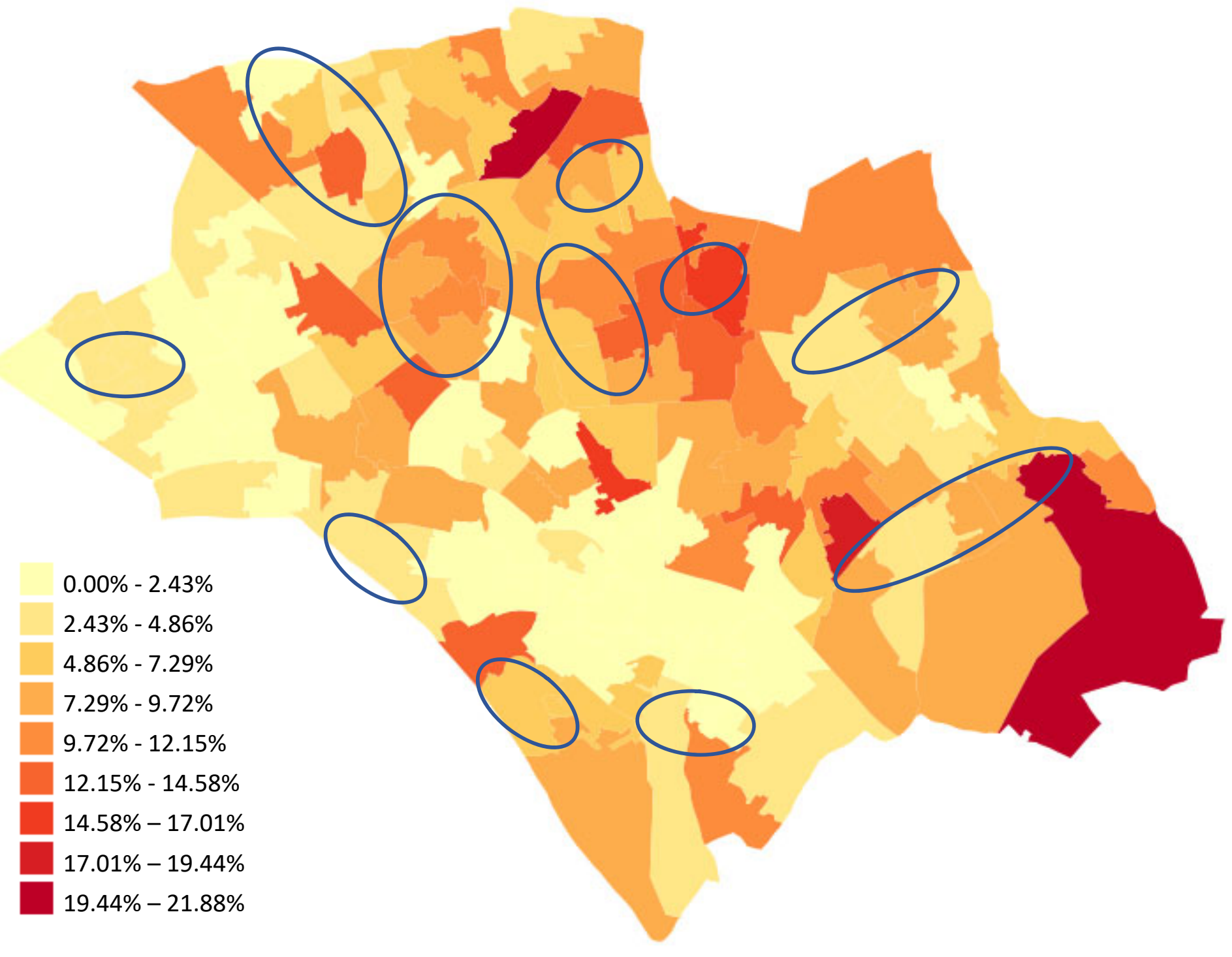

